\title{
EL PROGRAMA DE CUMPLIMIENTO COMO OBJETO DE PRUEBA EN EL PROCESO PENAL CONTRA LA PERSONA JURÍDICA
}

\author{
THE PROGRAM OF COMPLIANCE AS AN OBJECT OF TESTING \\ IN THE CRIMINAL PROCESS AGAINST THE LEGAL PERSON
}

\author{
Mtro. Renzo Espinoza Bonifaz \\ Maestro en Derecho con mención en Ciencias Penales \\ Universidad de San Martín de Porres \\ aespinozab@usmp.pe
}

Perú

\section{SUMARIO}

- Responsabilidad de las personas jurídicas

- El programa de cumplimiento como herramienta de prevención eficaz

- La persona jurídica como sujeto en el proceso penal

- El programa de cumplimiento como objeto de prueba en el proceso penal

- Conclusiones

\section{RESUMEN}

Este artículo busca dar a conocer el tratamiento probatorio de los programas de cumplimiento dentro de un proceso penal seguido en contra de una persona jurídica. Se precisa cómo debe ejecutarse un programa de cumplimiento en el interior de una empresa para lograr eficacia en el control y prevención de sus riesgos. También se detalla cómo la persona jurídica, en su condición de sujeto procesal, debe acreditar la efectividad de dicho programa de cumplimiento para eximirse de responsabilidad por la comisión de un delito realizado por un directivo o subordinado perteneciente a la organización empresarial.

\section{ABSTRACT}

The present article seeks to make known the probative treatment of compliance programs in a criminal proceeding followed against a legal entity. It is necessary to execute a compliance program within a company to achieve effective control and prevention of risks. It also details how the legal entity, in its status as a procedural subject, must prove the effectiveness of said compliance program in order to be exempt from liability for the commission of an offense carried out by a manager or subordinate belonging to the business organization.

\section{PALABRAS CLAVE}

Programa de cumplimiento, prueba penal, persona jurídica, proceso penal

\section{KEYWORDS}

Compliance program, criminal trial, legal person, criminal proceedings

\section{RESPONSABILIDAD DE LAS PERSONAS JURÍDICAS}

A través de la Ley N. ${ }^{\circ} 30424$ - publicada el 21 de abril de 2016 y modificada posteriormente mediante Decreto Legislativo N. ${ }^{\circ} 1352$ de fecha 7 de enero de 2017 - se ha establecido la responsabilidad «administrativa» de la persona jurídica por los delitos de cohecho activo, financiamiento de terrorismo y lavado de activos, cuando estos hayan sido cometidos en su nombre o por cuenta de ella y en su beneficio, directo o indirecto, por: a) Sus socios, directores, administradores de hecho o derecho, representantes legales o apoderados de la persona jurídica, o de sus filiales o subsidiarias; b) La persona natural que, estando sometida a la autoridad y control de las personas mencionadas en el literal anterior, haya cometido el delito bajo sus órdenes o autorización; y c) La persona natural señalada en el literal precedente, cuando la comisión del 
delito haya sido posible porque las personas mencionadas en el literal a) han incumplido sus deberes de supervisión, vigilancia y control sobre la actividad encomendada, en atención a la situación concreta del caso.

De esta manera, queda claro que nuestros legisladores aún no se atreven a derogar el viejo principio societas delinquere non potest, por lo menos en el plano formal, pues la ley hace mención a una responsabilidad «administrativa» de las personas jurídicas y no a una responsabilidad penal. Ello, a nuestro criterio, resulta un subterfugio lingüístico, fraude de etiqueta a lo que en realidad es la vigencia de la responsabilidad penal de las personas jurídicas.

Desde nuestro punto de vista, la decisión legislativa de sancionar administrativa $o$ penalmente a las personas jurídicas se justifica por el considerable avance de la criminalidad empresarial organizada en nuestro país. De acuerdo con sus características propias, este factor tiene una notable capacidad de adaptarse a las nuevas realidades sociales, identificando las fisuras en la organización social de un Estado que le permitan actuar y desarrollarse impunemente.

Que este tipo de criminalidad sea organizada pone de manifiesto que se trata de estructuras con algún grado de jerarquización y que dificultan una investigación criminal, pues en no pocos casos se presentan problemas para determinar la atribución de responsabilidad penal, dada la separación espacio-temporal entre la decisión de los jerarcas y la ejecución del delito. A ello debe sumarse su gran capacidad económica, que les permite, incluso, desestabilizar las instituciones políticas de un Estado a través de la corrupción de sus funcionarios. (Carnevali, 2010, p. 276)

Así, queda en evidencia el inminente peligro que ostenta este tipo de criminalidad, pues debilita las instituciones estatales hasta resquebrajar las bases de un Estado de derecho. En tal razón, resulta apremiante la adopción de medidas para defender las estructuras democráticas y sus medios de control a través de mecanismos eficaces, y no solo punitivos, para desarticular esta clase de organizaciones criminales.

Es necesario anotar que muchas de estas organizaciones criminales son aparentemente personas jurídicas que incursionan en actividades económicas lícitas, y precisamente valiéndose de esta apariencia, cometen delitos que socaban profundamente el mercado y, por ende, la estructura social de todo Estado.

Por razones de política criminológica, no podemos seguir enfrentándonos a este tipo de criminalidad con un derecho penal pensado para delitos de siglos pasados, pues la dogmática penal que lo sustenta no es adecuada para enfrentar estos nuevos retos. Y es que se trata de un derecho penal para delitos individuales, que normalmente requieren de un resultado y lesión perceptibles a través de los sentidos. Por su parte, las organizaciones criminales son entidades poderosas que usualmente realizan actividades que ponen en peligro bienes jurídicos colectivos, que dañan el orden económico, la salud pública o el correcto funcionamiento de la administración pública de un Estado.

De esta forma, resulta más que evidente que la lucha contra este flagelo requiere de instrumentos que anticipen oportunamente los daños sociales que producen los delitos cometidos por la organización criminal. La sanción solo de los representantes que actúan en nombre de la empresa es exigua para combatirla, y es que un sistema de prevención y sanción de delitos basados en la sanción de personas naturales deja intacta la organización criminal que promueve su comisión.

Por otro lado, queda claro que la ley en mención introduce el modelo de defecto de organización o modelo de responsabilidad por el hecho propio de la persona jurídica, en el que la atribución de su responsabilidad se debe a un defecto organizativo de la misma que permite la actuación delictiva de uno de sus representantes o colaboradores. Para este modelo de responsabilidad, se requiere la verificación de un defecto de organización en la persona jurídica y la existencia de una cultura empresarial de incumplimiento de la legalidad. De ello se desprende la necesidad de demostrar en un proceso penal que la conducta delictiva de su representante o colaborador se produjo debido a este defecto organizativo, lo cual constituye el hecho propio de la persona jurídica.

En este orden de ideas, la persona jurídica no será responsable si realiza una adecuada prevención de los riesgos inherentes a sus 
The program of compliance as an object of testing in the criminal process against the legal person

actividades económicas a través de un debido control y vigilancia sobre el personal de la empresa, detectando razonablemente la comisión de delitos desde la organización empresarial. Es ahí que cobran importancia los programas de cumplimiento, dispositivos internos que las empresas implementan para cumplir con la normatividad vigente, así como para prevenir y detectar las infracciones legales que se produzcan dentro de las mismas o como parte de las actividades que estas realizan (Wellner, 2005, p. 501).

La implementación eficaz de estos programas da lugar a una eximente de responsabilidad de la persona jurídica. Así lo establece el artículo $17^{\circ}$ de la Ley N. ${ }^{\circ} 30424$ :

La persona jurídica está exenta de responsabilidad por la comisión de los delitos comprendidos en el artículo 1, si adopta e implementa en su organización, con anterioridad a la comisión del delito, un modelo de prevención adecuado a su naturaleza, riesgos, necesidades y características, consistente en medidas de vigilancia y control idóneas para prevenir los delitos antes mencionados o para reducir significativamente el riesgo de su comisión.

Es más, la ley establece que los programas de cumplimiento deben contar con los siguientes elementos mínimos:

1. Un encargado de prevención, designado por el máximo órgano de administración de la persona jurídica o quien haga sus veces, según corresponda, que debe ejercer su función con autonomía. Tratándose de las micro, pequeñas y medianas empresas, el rol de encargado de prevención puede ser asumido directamente por el órgano de administración.

2. Identificación, evaluación y mitigación de riesgos para prevenir la comisión de los delitos previstos en el artículo $1 .^{\circ}$ a través de la persona jurídica

3. Implementación de procedimientos de denuncia

4. Difusión y capacitación periódica del modelo de prevención

5. Evaluación y monitoreo continuo del modelo de prevención
De esta manera, y conscientes de la importancia y trascendencia jurídico-penal que revela esta herramienta de prevención en personas jurídicas, es esencial analizar cómo demostrar que es idónea para reducir razonablemente los riesgos inherentes de la empresa que la ha implementado y que funciona correctamente en el seno de la organización empresarial.

\section{EL PROGRAMA DE CUMPLIMIENTO COMO HERRAMIENTA DE PREVENCIÓN EFICAZ}

Los programas de cumplimiento tienen el fin mediato o trascendente de generar en la persona jurídica una cultura de cumplimiento basada en la integridad de sus colaboradores, logrando que ellos internalicen valores sólidos. No obstante, su fin inmediato persigue alinear los objetivos de la corporación con la observancia de la normativa jurídica respectiva.

Debemos ser enfáticos en señalar que no se trata de normar lo ya normado a través de los programas de cumplimiento. Existen leyes penales de obligatorio cumplimiento para todos los ciudadanos y, por tanto, también para los colaboradores que integran la persona jurídica.

Es necesario saber utilizar el programa de cumplimiento como una herramienta para promover hábitos éticos en el seno de toda empresa, ya que, si solo la enfocamos en «cumplir», no se tendrá el éxito deseado. Las leyes penales también se deben «cumplir», y muy pocas personas lo hacen.

En este orden de ideas, para que dicho programa de cumplimiento sea eficaz - es decir, que utilice los mínimos recursos y logre sus objetivos-, se requiere de un constante trabajo de perfeccionamiento de su contenido y procedimientos. Por ello, es esencial entender que todo programa de cumplimiento debe estar asentado en tres columnas fundamentales: prevención, detección y reporte, y resolución.

\section{Prevención}

Como ya hemos señalado en los apartados anteriores, el éxito del programa de cumplimiento radica en el hecho de configurase como una herramienta idónea de anticipación, en el ámbito privado, de las posibles conductas desviadas producidas en el seno de las personas jurídicas. Por tanto, esta etapa debe buscar 
impedir la comisión de delitos por parte de los colaboradores de la empresa.

Como primer punto, se deben identificar las actividades y sectores de la empresa en donde se pueden llegar a cometer delitos. Una vez evaluados estos riesgos, se deben diseñar e implementar los protocolos y procedimientos que permitan la prevención de delitos en dichos sectores. Para ello, se elaborará un código de conducta ética, un protocolo de políticas para la toma de decisiones, un procedimiento de vigilancia y control con un sistema de incentivos y sanciones, etc.

El éxito de los protocolos y procedimientos dependerá de la capacitación efectiva de las áreas encargadas de aplicarlos y velar por su observancia. Estas áreas, a su vez, deben sensibilizar a todos los colaboradores de la empresa sobre la importancia del cumplimiento, sobre todo a los consejeros y directivos, pues, siendo líderes de la corporación, tienen influencia directa en las actitudes de sus colaboradores. Solo a través de la práctica diaria de acciones y hábitos positivos se logrará generar una cultura corporativa basada en la integridad ética. Un factor necesario en este sentido es comunicar a todos el comportamiento positivo de algún colaborador de la empresa e incentivarlos a la participación dentro de la corporación, ya sea para plantear sus dudas o brindar una sugerencia respecto a los protocolos y procedimientos adoptados.

Hemos señalado anteriormente que es un componente trascendental escuchar a los colaboradores de la empresa al momento de establecer los valores corporativos. Solo de esta forma se puede conseguir una identificación real con los mismos. De igual manera, es recomendable establecer políticas de contratación y promoción de los colaboradores basadas en méritos; ello creará un clima laboral altamente deseable.

\section{Detección y reporte}

Esta etapa resulta ser relevante en el modelo de prevención, pues la persona jurídica será responsable de aquellos delitos producidos por una omisión de sus deberes de supervisión, vigilancia y control; sin embargo, si la empresa demuestra que el programa de cumplimiento adoptado es idóneo para detectar y reportar oportunamente dichos delitos, quedará exenta de responsabilidad.
Para identificar las zonas en donde se puede producir un incumplimiento por comportamientos irregulares de los colaboradores, se debe implementar una oficina de cumplimiento que monitorice la adecuación de las actividades empresariales al programa de cumplimiento adoptado. Además, esta oficina puede establecer un canal de denuncias, confidencial y anónimo, que reciba noticias sobre conductas indebidas, infracciones y posibles comportamientos que generen responsabilidad penal, disponible tanto para colaboradores como para clientes de la persona jurídica.

Por otra parte, los procedimientos de investigación iniciados a partir de las denuncias recibidas, deben permitir esclarecer el suceso referido respetando las garantías de presunción de inocencia, derecho de defensa, legitimidad en la obtención de la prueba, etc. En todo momento se debe velar por el derecho fundamental al debido proceso del colaborador involucrado en dicho procedimiento.

También es necesario revisar constantemente el programa de cumplimiento para localizar posibles fallas y corregirlas. Ello permitirá medir el desempeño del programa en relación con los objetivos establecidos. Finalmente, se deben obtener resultados concretos, pues un programa de cumplimiento que no detecte y reporte, no será eficaz, ya que es una utopía sostener que en una empresa no existen conductas irregulares entre sus colaboradores.

\section{Resolución}

Si se detecta un incumplimiento, además de sancionar, el programa de cumplimiento debe minimizar o compensar el impacto generado por la conducta irregular. Para ello se deben subsanar las deficiencias detectadas en el programa con la finalidad de evitar la reincidencia, aunque ello signifique la modificación del modelo de prevención, pues las fallas en el funcionamiento deben ser inmediatamente analizadas para mejorar el protocolo o procedimiento que ha funcionado defectuosamente. $Y$ es que la vorágine empresarial y los cambios legislativos pueden desfasar rápidamente una actividad comercial hasta ser necesario establecer una nueva regulación corporativa interna. 
Es imprescindible documentar las etapas de adopción, implementación $\mathrm{y}$ funcionamiento del programa de cumplimiento, pues para lograr la exención de responsabilidad se requiere demostrar que es un modelo de prevención adecuado a la naturaleza, riesgos, necesidades y características de la persona jurídica, y que cuenta con medidas de vigilancia y control idóneas para prevenir delitos o para reducir significativamente el riesgo de su comisión. Asimismo, la oficina de cumplimiento debe gozar de independencia y autoridad dentro de la persona jurídica, tener la atribución de solicitar información, ser escuchada por los directivos y consejeros, contar con recursos humanos y materiales adecuados, así como constante apoyo de la gerencia general.

\section{Ventajas y criticas}

Un programa de cumplimiento eficaz no solo permite que la empresa cumpla con los requerimientos normativos y que evite ser sancionada, sino también que genere una mayor rentabilidad y productividad, pues, al mantener a la alta dirección informada sobre el desempeño de la corporación, se toman mejores decisiones comerciales. Esto redunda en el éxito de la empresa como unidad económica productiva. Además, la transparencia en la información que maneja la empresa respecto a sus procedimientos $\mathrm{y}$ protocolos internos incrementa la buena imagen que pueda tener en el mercado frente a accionistas y clientes, generando una mayor valorización de sus acciones.

No obstante, como toda invención humana no está exenta de críticas, puede suceder que los programas de cumplimiento se utilicen como un instrumento de blindaje de la alta dirección de la persona jurídica para evitar la persecución y sanción penal, desnaturalizando la razón de ser de esta herramienta.

Un programa de cumplimiento en el cual predomine excesivamente la vigilancia $y$ control de sus colaboradores puede generar un clima laboral de desconfianza e inseguridad, repercutiendo negativamente en su desempeño y motivación. Esta situación reduciría ostensiblemente su eficiencia.

\section{LA PERSONA JURÍDICA COMO SUJETO EN EL PROCESO PENAL}

Una de las novedades del Código Procesal Penal del 2004, aprobado mediante el Decreto
Legislativo $\mathrm{N} .{ }^{\circ}$ 957, es que introduce a la persona jurídica como sujeto procesal en el Título III de la Sección IV del Libro I, artículos 90. ${ }^{\circ}$ al $93 .^{\circ}$.

En él se establece que las personas jurídicas siempre que sean pasibles de imponérseles las medidas previstas en los artículos $104^{\circ}$ y $105^{\circ}$ del Código Penal- deberán ser emplazadas e incorporadas en el proceso a instancia del fiscal. Lo dispuesto se enmarca en el contexto de la posible imposición de consecuencias accesorias a la organización empresarial, cuando el hecho punible fuere cometido en ejercicio de la actividad de cualquier persona jurídica o utilizando su organización para favorecerlo o encubrirlo. Esta consideración debe extenderse, desde nuestro criterio, a los casos de una posible imposición de las medidas «administrativas» establecidas en el artículo $5^{\circ}$ de la Ley N. ${ }^{\circ} 30424$.

La persona jurídica, incorporada debidamente en el proceso penal, goza de todos los derechos y garantías que se le concede al imputado. Para tales efectos, su máximo órgano de representación social debe designar un apoderado judicial, no pudiendo ser quien se encuentre imputado por los mismos hechos. Ello obedece a que la teoría del caso de la persona jurídica puede ser distinta a la de la persona natural procesada por los mismos hechos.

De esta manera, el apoderado judicial tiene la capacidad de comparecer al proceso en representación de la persona jurídica, gozando de todas las atribuciones y potestades generales que le corresponden a esta, salvo aquellas para las que la ley exige facultades expresas; ello en aplicación del artículo $74 .^{\circ}$ del Código Procesal Civil, el cual, de acuerdo con la Primera Disposición Complementaria y Final de dicho cuerpo normativo, se aplica supletoriamente a los demás ordenamientos procesales, siempre que sean compatibles con su naturaleza.

Así, el apoderado judicial tiene el derecho de conocer los cargos formulados en contra de la persona jurídica de manera inmediata y detallada; ser asistido desde los actos iniciales de la investigación por un abogado defensor de su elección o de oficio; abstenerse de declarar, y si acepta, a que su abogado defensor esté presente en su declaración y en todas las diligencias en que se requiere su presencia; y que no se empleen en su contra 
medios coactivos, intimidatorios o contrarios a su dignidad, ni a ser sometido a técnicas o métodos que induzcan o alteren su libre voluntad o a sufrir una restricción no autorizada ni permitida por ley.

Asimismo, el apoderado tiene el derecho inviolable e irrestricto a que se le informe de sus derechos, a que se le conceda un tiempo razonable para que prepare su defensa, a ejercer su autodefensa material, a intervenir, en plena igualdad, en la actividad probatoria, $\mathrm{y}$, en las condiciones previstas por la ley, a utilizar los medios de prueba pertinentes. Su ejercicio del derecho de defensa se extiende a todo estado y grado del procedimiento, en la forma y oportunidad que la ley señala. También tiene derecho a deducir los medios de defensa técnicos que estime pertinentes, a cuestionar la competencia objetiva y subjetiva del juez que conoce su caso, a interponer los medios impugnatorios previstos en la ley cuando considere que una resolución judicial lo agravia, o la nulidad en contra de las actuaciones procesales que estime incumplan las disposiciones legales.

\section{EL PROGRAMA DE CUMPLIMIENTO COMO OBJETO DE PRUEBA EN EL PROCESO PENAL}

Luego de todo lo expuesto, es comprensible la necesidad de los programas de cumplimiento para determinar en qué medida la persona jurídica cumplió con los deberes de supervisar, vigilar y controlar las actividad de sus miembros, manteniendo los riesgos inherentes a su actividad comercial en niveles aceptables.

Por ello, la implementación idónea de un programa de cumplimiento debe ser objeto de investigación y prueba en todo proceso penal que tenga como sujeto de imputación a la persona jurídica. Sin embargo, debemos ser prudentes al momento de valorar la adopción de dichos programas de cumplimiento, puesto que no se trata de una prueba absoluta que por sí sola pueda demostrar ausencia de responsabilidad de la persona jurídica.

Lo trascendental al momento de evaluar la responsabilidad de las personas jurídicas es el efectivo cumplimiento de los deberes de supervisión y control sobre la actividad concreta en la que se ha perpetrado la conducta delictiva, no obstante de que los programas de cumplimiento puedan demostrar la voluntad de la entidad de hacer efectivas dichas obligaciones. Desde esta perspectiva, se deben tener en cuenta los siguientes criterios para evaluar la importancia de los programas de cumplimiento en relación con la responsabilidad de la persona jurídica:

1. Ante todo, demostrar la eficacia de los programas de cumplimiento, acreditar que sirven para prevenir y detectar los posibles delitos que pudieran cometerse al interior de la organización empresarial.

2. Acreditar que estén adecuadamente implementados, esto es, comprobar la aplicación en tiempo real de los procedimientos y protocolos por parte de sus administradores y colaboradores con la finalidad de revelar la vigencia actual del programa.

3. Ante la comisión de un delito, debe acreditarse que su ocurrencia es un hecho eventual, y que no se debe a la falta de control y vigilancia por parte de la persona jurídica.

La adopción de un programa de cumplimiento eficaz no es el único medio de prueba para acreditar el cumplimiento de los deberes de supervisión, vigilancia y control por parte de la organización empresarial. Su inexistencia no significa, por tanto, que el control ejercido sobre sus colaboradores haya sido exiguo, pues resulta posible que la persona jurídica disponga otro tipo de medidas que cumplan la misma función que los programas de cumplimiento. En este orden de ideas, queda claro que el juzgador debe valorar el programa de cumplimiento conjuntamente con otros medios de prueba con la finalidad de determinar si la persona jurídica actuó de manera diligente en el control de los riesgos delictivos derivados de su actividad.

Consideramos un error del legislador establecer en el artículo $12^{\circ}$ de la Ley N. 30424 que la acreditación parcial de los elementos mínimos del programa de cumplimiento solo permite una atenuación de la responsabilidad de la persona jurídica, pues le resta libertad al juzgador para realizar una correcta valoración de la culpabilidad empresarial, observándose que la referida ley pretende reducir su apreciación al mero cumplimiento formal de los referidos 
The program of compliance as an object of testing in the criminal process against the legal person

elementos mínimos. Así, de lege ferenda, resultaría más adecuada una regulación menos taxativa al respecto.

\section{Los medios de prueba pertinentes para acreditar la eficacia del programa de cumplimiento}

Ya determinado que el programa de cumplimiento es relevante como objeto de prueba para acreditar o no la culpabilidad empresarial, se requiere precisar qué medios de prueba son pertinentes y útiles para acreditar su existencia, así como su efectiva implementación y prevención.

En primer lugar, la existencia de todo programa de cumplimiento se podrá acreditar a través de medios de prueba documentales. Así, se deberá acompañar el conjunto de documentos que integran en su totalidad el programa de cumplimiento: código de ética, protocolos de procedimientos de actuación orientados a prevenir, detectar y resolver la comisión de posibles delitos, diseño del modelo de organización y gestión del departamento de cumplimiento, etc. Además, para verificar la vigencia actual del programa de cumplimiento - esto es, su efectiva y real implementación-, resulta fundamental aportar el archivo y registro documental de su actividad, es decir, los documentos generados a raíz de la puesta en marcha del programa; por ejemplo, la información recibida a través del canal de denuncias, las indagaciones internas realizadas como consecuencias de dichas acusaciones y las eventuales sanciones dictadas; también los informes del departamento de cumplimiento respecto a las revisiones constantes del sistema de prevención y detección de riesgos como de las capacitaciones ofrecidas a los colaboradores de la organización empresarial con la finalidad de crear una cultura corporativa de cumplimiento.

Por otro lado, las pericias y testimoniales son también útiles y pertinentes para acreditar la eficacia del programa de cumplimiento. De esta forma, las declaraciones testimoniales de los oficiales de cumplimiento, administradores, colaboradores y clientes de la persona jurídica son de vital importancia para demostrar la idoneidad de los controles implementados a través del programa de cumplimiento. De igual manera, las pericias de profesionales expertos en relación con la adecuación de los programas de cumplimiento - -según la naturaleza, riesgos, necesidades y características propias de la organización empresarial- permitirán determinar si el modelo adoptado es apto para prevenir y/o detectar los posibles delitos en el seno de la entidad.

En este sentido, el artículo $18 .^{\circ}$ de la Ley $\mathrm{N} .{ }^{\circ} 30424$ establece que, para formalizar la investigación preparatoria, el fiscal debe contar con un informe técnico de la Superintendencia del Mercado de Valores (SMV) que analice la implementación y funcionamiento del modelo de prevención, que tiene valor probatorio de pericia institucional. Si el informe técnico de la SMV establece que la implementación y funcionamiento del modelo de prevención antes de la comisión del delito es adecuado, el fiscal dispone del archivo de lo actuado mediante decisión debidamente motivada. Así, la Octava Disposición Complementaria Final de la ley en mención prescribe que dicho informe técnico constituye un requisito de procedibilidad para la formalización de la investigación preparatoria por los delitos contenidos en el artículo $1^{\circ}$ de la norma referida.

No obstante, el juez debe controlar el grado de aceptación de las conclusiones de los peritos, así como la razonabilidad y fiabilidad de los procedimientos realizados, ya que, si al perito le toca resolver un problema científico o una duda técnica, al juez le corresponde resolver el problema del proceso, que es siempre un problema humano y de proyección social (Vázquez, 1985, p. 478).

Un testigo imprescindible es el oficial de cumplimiento, pues además de poder relatar cómo se implementó y cómo funciona el programa de cumplimiento, puede precisar si ha resultado idóneo para controlar los riesgos delictivos propios de la actividad de la organización empresarial. Igualmente, otros dirigentes o colaboradores de la persona jurídica, sobre todo en el ámbito en donde se produjo el presunto delito, podrán ser interrogados sobre cómo funcionan las medias preventivas, protocolos $\mathrm{y}$ procedimientos establecidos en el programa de cumplimiento, es decir, si realmente se encuentra en vigencia el modelo de prevención adoptado por la persona jurídica.

En suma, los medios de prueba documentales son útiles para comprobar la idoneidad de la 
implementación del programa de cumplimiento que controla los riesgos específicos de la actividad de la persona jurídica, vale decir, si al momento de diseñar el modelo de prevención se tuvieron en cuenta las características y necesidades propias de la organización empresarial, su estructura y naturaleza particular. Dichos medios probatorios deben ser complementados por pericias que ofrezcan una apreciación de la eficacia del programa de cumplimiento antes y durante su ejecución, y por testimoniales que demuestren que efectivamente se está ejecutando dicho programa de cumplimiento, demostrándose que el modelo de prevención fue adaptado a la estructura organizativa de la persona jurídica.

\section{La carga de la prueba sobre la eficacia del programa de cumplimiento}

Para resolver la interrogante de a quién le corresponde probar ante el juzgador la idoneidad y eficacia de los programas de cumplimientos implementados para controlar los riesgos de la organización empresarial, es necesario determinar cuál es la naturaleza jurídica de los mismos dentro de la teoría del delito.

De esta manera, un sector de la doctrina entiende que el incumplimiento de los deberes de control y vigilancia es el sustento y fundamento de la culpabilidad de la persona jurídica por defecto organizativo, y el otro señala que la existencia de un programa de cumplimiento adecuado e idóneo para prevenir y controlar los riesgos inherentes a la actividad de la persona jurídica resulta ser una circunstancia eximente de responsabilidad penal. Para los primeros, el encargado de probar la culpabilidad empresarial sería el Ministerio Público; por tanto, le correspondería demostrar en el proceso penal que el programa de cumplimiento implementado por la persona jurídica es solo formal y que no funciona eficazmente para prevenir los riesgos inherentes a su actividad comercial. Para los otros, al constituir la implementación de un programa de cumplimiento un eximente de responsabilidad penal, le correspondería a la persona jurídica acreditar su idoneidad $\mathrm{y}$ eficacia en el proceso penal, aportando medios de prueba útiles y pertinentes que puedan demostrar que dicho programa es adecuado para prevenir y mitigar los posibles delitos inherentes a las características propias de su actividad.
Teniendo en cuenta la teoría dinámica de la carga de la prueba, que señala que le corresponde probar a aquel sujeto que, en principio, tiene más facilidades para aportar las evidencias requeridas, la Fiscalía General del Estado de España - mediante la circular 1/2016 - ha indicado que es la propia empresa la que cuenta con los recursos y con mayores posibilidades de acreditar que su programa era eficaz y que cumplía con los estándares exigidos legalmente, pese a la comisión del delito, al encontrarse en las mejores condiciones de proporcionar de manera única e insustituible los datos que atañen a su organización. (p. 57)

Otro argumento utilizado por la Fiscalía General del Estado de España para hacer recaer sobre la organización empresarial la carga de probar la eficacia de su programa de cumplimiento se fundamenta sobre la lógica de la prueba por indicios. En este sentido, manifiesta que «la atribución a la persona jurídica de la carga de la prueba deriva [...] del hecho de que la propia comisión del delito opera como indicio de la ineficacia del modelo y que, sobre esta base, cabría exigir a la persona jurídica una explicación exculpatoria que eliminara el efecto incriminatorio del indicio».

El artículo $17^{\circ}$ de la Ley N. ${ }^{\circ} 30424$ establece una eximente de responsabilidad de la persona jurídica si adopta e implementa en su organización, con anterioridad a la comisión del delito, un modelo de prevención adecuado a su naturaleza, riesgos, necesidades y características, consistente en medidas de vigilancia y control idóneas para prevenir los delitos o para reducir significativamente el riesgo de su comisión. Dicho esto, podría afirmarse, conforme a nuestra normativa, que le correspondería a la persona jurídica demostrar la implementación de los programas de cumplimiento de manera eficaz en su organización empresarial. Se debe tener en cuenta que la norma en mención señala un conjunto de elementos que deben concurrir mínimamente al momento de adoptarse el programa de cumplimiento, los cuales deben ser acreditados a efectos de ser beneficiados con la eximente de responsabilidad.

Por otro lado, el numeral 4 del artículo $17^{\circ}$ prescribe que «se excluye también la responsabilidad de la persona jurídica cuando cualquiera de las personas naturales señaladas en el artículo $3^{\circ}$ comete el delito eludiendo de 
The program of compliance as an object of testing in the criminal process against the legal person

modo fraudulento el modelo de prevención debidamente implementado». Sin embargo, las personas comprendidas en el artículo $3^{\circ}$ ocupan jerarquías distintas en la estructura organizacional de la persona jurídica. Así tenemos por un lado a: 1) socios, directores, administradores de hecho o derecho, representantes legales o apoderados de la persona jurídica; $\mathrm{y}$, por el otro, b) personas naturales que, estando sometidas a la autoridad $y$ control de las personas mencionadas en el numeral anterior, hayan cometido el delito bajo sus órdenes o autorización; o cuando la comisión del delito haya sido posible porque las personas mencionadas en el numeral anterior han incumplido sus deberes de supervisión, vigilancia y control sobre la actividad encomendada en atención a la situación concreta del caso.

Consideramos un grave error de la norma equiparar la actuación de un representante legal o directivo de la empresa con la de un subordinado, puesto que si tenemos en cuenta que la actuación de un funcionario que ostenta un alto cargo directivo en la empresa es manifestación de la política organizacional de la misma, su conducta resulta intrínseca a la cultura corporativa de la organización.

Por tanto, entendiendo que los altos cargos de la persona jurídica son los responsables de diseñar una política empresarial que promueva una cultura de cumplimiento de la normatividad al interior de la organización, y de controlar y vigilar los riesgos inherentes a su actividad, es infrecuente sostener que ellos puedan cometer un delito eludiendo fraudulentamente el programa de cumplimiento. Ello revelaría la inexistencia de un programa de cumplimiento idóneo, no resultando creíble la eficacia de un modelo de prevención sin el compromiso y apoyo pleno de la alta dirección de la persona jurídica, demostrándose que esta no se encuentra organizada correctamente o, en todo caso, existiendo una firme presunción al respecto.

Desde un punto de vista probatorio, ello conllevaría a que a la persona jurídica le corresponda acreditar que, pese a que un alto funcionario de su organización cometió un delito, el programa de cumplimiento resulta idóneo para prevenirlos o para reducir significativamente el riesgo de su comisión, invirtiéndose la carga de la prueba. Esta afirmación es lógica, ya que, si un funcionario de la más alta jerarquía de la entidad cometió un delito burlando el modelo de prevención implementado, se puede deducir un defecto organizativo en el control de los riesgos penales desde el nivel más importante de la empresa, infiriéndose indiciariamente que los deberes de dirección y supervisión no están funcionado adecuadamente.

No obstante, tal presunción admite prueba en contrario, por lo que la persona jurídica, para quedar exenta de responsabilidad, debe demostrar que tenía un programa de cumplimiento idóneo para prevenir el delito supuestamente perpetrado, que existía un oficial o departamento de cumplimento, autónomo e independiente respecto de la alta dirección de la organización, y que el alto funcionario que cometió el delito lo realizó fraudulentamente, evadiendo el modelo de prevención que la entidad tenía implementado para prevenir o reducir el riesgo de comisión de delitos en su seno, es decir, que engañó dolosamente al oficial de cumplimiento.

Por otro lado, en el caso de que el delito fuera cometido por un subordinado, el acusador debe acreditar que su actividad delictiva, además de haber sido cometida en nombre de la persona jurídica o por cuenta de ella $\mathrm{y}$ en su beneficio, directo o indirecto, fue posible por el incumplimiento de los deberes de supervisión, vigilancia o control en las actividades encomendadas por parte de los altos funcionarios u órganos responsables de tales deberes.

En este orden de ideas, la persona jurídica solo responderá si se comprueba una omisión de sus deberes de vigilancia y control que haya ocasionado un riesgo jurídicamente desaprobado que facilita la comisión de un delito en su beneficio, por alguno de sus subordinados, en el ejercicio de sus cargos en la entidad.

El Ministerio Público debe aportar medios de prueba suficientes que acrediten la omisión de control y vigilancia en el área de la organización en que presuntamente se cometió el delito, la incorrecta distribución de responsabilidades entre los órganos de la entidad, la falta de supervisión sobre los subordinados, la insuficiencia o inexistencia de un régimen disciplinario para quienes incumplan el programa de cumplimiento, la 
falta de medidas apropiadas para prevenir y descubrir conductas delictivas, o cualquier otro defecto organizativo de la entidad, de las cual se pueda inferir una falta de control de los riesgos inherentes a su actividad.

Por su lado, la defensa de la persona jurídica podrá ofrecer medios de prueba que demuestren la existencia de un programa de cumplimento eficaz e idóneo, adecuado a la naturaleza y características propias de la organización empresarial y, sobre todo, operativo.

Finalmente, no se debe olvidar que los principios de presunción de inocencia e in dubio pro reo también son aplicables a la persona jurídica como sujeto procesal que goza de las mismas garantías procesales que las que le corresponden al imputado. Por tanto, si el juzgador tiene dudas sobre la concurrencia de la omisión de los deberes de vigilancia y control por parte de la entidad, deberá excluirla de responsabilidad.

\section{CONCLUSIONES}

El programa de cumplimiento es una herramienta sumamente eficaz para controlar los riesgos inherentes de la actividad específica de toda persona jurídica. Su adecuada aplicación permite detectar oportunamente los actos preparatorios de posibles delitos por parte de los directivos y colaboradores de la organización empresarial.

Para que un programa de cumplimiento sea considerado idóneo debe haber sido implementado efectivamente, es decir, debe responder a las características y naturaleza propias de la persona jurídica, sus protocolos y procedimientos deben estar actualizados, y su ejecución debe verificarse en tiempo real.

El desarrollo de todo programa de cumplimiento debe confiársele a una oficina o departamento que goce de autonomía e independencia, que cuente con los recursos humanos y materiales necesarios para garantizar que durante su desarrollo vaya a cumplir el deber de vigilancia y control de las actividades de los directivos y colaboradores que conforman la organización empresarial.

En el marco de un proceso penal en contra de la persona jurídica, la eficacia del programa de cumplimiento debe ser demostrada a través de medios de prueba que acrediten la existencia, vigencia y efectividad del mismo, y, por sobre todo, que comprueben la observancia de los deberes de vigilancia y control de la entidad corporativa. Los medios de prueba que se pueden ofrecer para demostrar la eficacia del programa de cumplimento pueden ser documentales, aportando no solo el modelo de prevención en sí, sino también todos los documentos generados con su implementación y su ejecución; a ellos se les puede sumar las testimoniales de los dirigentes y colaboradores de la empresa, los cuales relatarán cómo se ha ejecutado el programa de cumplimiento en el seno de la entidad, y, en su caso, las pericias de un auditor del programa o del oficial de cumplimiento, el que incluso podría ser ofrecido como testigo experto.

Constitucionalmente, como titular de la acción penal y la carga de la prueba, al fiscal le corresponde probar que la persona jurídica, tiene un defecto organizativo que no le ha permitido controlar adecuadamente los riesgos inherentes a su actividad, lo cual ha generado que uno de sus miembros haya cometido un delito. Por su parte, y para eximirse de responsabilidad, la persona jurídica debe acreditar que se organizó diligentemente para prevenir y detectar posibles conductas delictivas que pudieran producirse en el desarrollo de su actividad específica, ya sea mediante la implementación de un programa de cumplimiento adecuado a su naturaleza y características propias, o a través de otras medidas o instrumentos idóneos para controlar y descubrir posibles actos ilícitos en su interior.

\section{REFERENCIAS}

Carnevali, R. (2010). La criminalidad organizada. Una aproximación al derecho penal italiano, en particular la responsabilidad de las personas jurídicas y la confiscación, 16(2). Revista Ius et Praxis, p. 273-330.

Código Penal (1991). Recuperado del sitio de internet del Sistema Peruano de Información Jurídica: http://spij.minjus.gob.pe/ $\mathrm{CLP} /$ contenidos.dll? $\mathrm{f}=\mathrm{id} \$ \mathrm{id}=$ peru\%3Ar\%3A14 $033 \$$ cid=peru $\$ \mathrm{t}=$ document-frame.htm $\$ \mathrm{an}=\mathrm{JD}$ salas $1315 \$ 3.0 \# J D$ salas 1315

Código Procesal Civil (1993). Recuperado del sitio de internet del Sistema Peruano de Información Jurídica: http://spij.minjus.gob.pe/ 

jurídica

The program of compliance as an object of testing in the criminal process against the legal person

$\mathrm{CLP} /$ contenidos. $\mathrm{dll}$ ? $\mathrm{f}=\mathrm{id} \$ \mathrm{id}=$ peru $\% 3 \mathrm{Ar} \% 3 \mathrm{~A} 10$ c $43 \$ \mathrm{cid}=$ peru $\$ \mathrm{t}=$ document-frame.htm $\$ \mathrm{an}=\mathrm{JD}$ Procesal_Civil\$3.0\#JD_Procesal_Civil

Código Procesal Penal. (2004). Recuperado del sitio de internet del Instituto de Defensa Legal del Perú: http://www.justiciaviva.org.pe/ nuevos/cpp-dec957.pdf

Fiscalía General del Estado de España. (22 de enero de 2016). Circular 1/2016 sobre la responsabilidad penal de las personas jurídicas conforme a la reforma del Código Penal efectuada por Ley Orgánica 1/2015. Madrid. Recuperado de https:// www.fiscal.es/fiscal/PA_WebApp_SGNTJ NFIS/descarga/CIRCULAR\%201-2016\%20 -\%20PERSONAS $\% 20$ JUR $\%$ C $3 \% 8$ DDICAS. pdf? idFile $=$ c c 42 d 8 fd- 09 e $1-4$ f5b-b38a$447 \mathrm{f} 4 \mathrm{f} 63 \mathrm{a} 041$
LeyN. ${ }^{\circ} 30424$, Leyqueregulalaresponsabilidad administrativa de las personas jurídicas por el delito de cohecho activo transnacional. (21 de abril de 2016). Recuperado del sitio de internet del diario oficial El Peruano: http://busquedas. elperuano.com.pe/normaslegales/ley-que-regulala-responsabilidad-administrativa-de-las-persley-n-30424-1370638-1/

Vázquez, J. (1985). Presunción de inocencia del imputado e íntima convicción del tribunal. Estudio sobre la utilización del imputado como fuente de prueba en el proceso penal español. Barcelona: Bosch, pp. 470-479.

Wellner, P. A. (2005). Effective Compliance Programs and Corporate Criminal Prosecutions. Cardozo Law Review, 27(1), pp. 497-528 